\title{
Fournier's Gangrene: Case Report
}

\author{
Ehab Ahmed \\ Department of Urology, South Stockholm Hospital, Stockholm, Sweden
}

\begin{abstract}
Fournier's gangrene (FG) is defined as a life-threatening polymicrobial necrotizing fasciitis affecting the genitalia and perineum. This report present a patient with Fournier's gangrene and describe the physical examination and CT scan finding together with the management and the postoperative follow-up. Early surgical intervention, haemodynamic support, intensive care monitoring and broad-spectrum antibiotic coverage, can reduce the mortality rate.
\end{abstract}

Keywords: Fournier's gangrene, necrotizing fasciitis, emergency medicine

\section{Introduction}

Fournier's gangrene (FG) is defined as a life-threatening polymicrobial necrotizing fasciitis affecting the genitalia and perineum, which can spread to the abdominal wall between the fascia planes. Most patients have an underlying systemic disorder that suppresses the immunity and increases susceptibility to polymicrobial infection [1]. The necrotizing process commonly arises from an anorectal infection and genitourinary tract infection. In addition, FG can also be caused by iatrogenic and non-iatrogenic perineal trauma [2]. Despite increased knowledge of the etiology, diagnosis and treatment, and intensive-care techniques, the mortality rate for FG is still high, at $20-43 \%$ in most series [2-6].

This report present a patient with Fournier's gangrene and describe the physical examination and CT scan finding together with the management and the postoperative followup.

\section{Case Report}

\subsection{Presentation}

A 92 year-old male with a past medical history significant for hypertension, prostate cancer under hormonal treatment, clean intermittent catheterization three times per day, and poorly controlled diabetes mellitus. He presented to the emergency department with fever, vomiting, and generalized weakness. His symptoms started 1 day prior to presentation. No other associated symptoms. Vital signs included a blood pressure of $127 / 88$, pulse of 98 , and temperature of 38,4 . Physical examination was unremarkable. Laboratory analysis revealed a C-reactive protein (CRP) of $286 \mathrm{mg} / \mathrm{L}$ $(<3 \mathrm{mg} / \mathrm{L})$, white blood cell of $34.0 \times 10^{9} / \mathrm{L}(3.5-8.8)$, serum creatinine of $207 \mathrm{mmol} / \mathrm{L}(<100 \mathrm{mmol})$.

\subsection{Initial management}

Foley catheter is inserted and patient admitted to the Urology ward as urinary tract infection. Patient started on intravenous (IV) Cefotaxime $1 \mathrm{~g} \mathrm{x}$.

\subsection{Progress}

In the next morning, patient developed fever (39.0), swelling and redness in the penis, scrotum, and lower abdomen. On physical examination, severe redness and swelling over the penis associated with gangrenous changes over the glans of the penis (fig 1).

Urgent CT scan of the abdomen and pelvis was done and revealed emphysematous changes with gas bubbles in the penile and perineal area, picture of Fournier gangrene. Patient directed to the operating theatre for surgical exploration and debridement.

\subsection{Procedure}

Diamond incision around the penis and the prenium was done. Complete necrosis and gangrenous changes affecting the corpora of the penis together with the urethra was identified. Trial to save the penis BUT due to deep necrosis in the corpora cavernosa and the urethra decided to do total penile amputation and urethrectomy. Both testicles were intact and viable. The wound left open and packed with aquacell gauze. Supra/pubic catheter was inserted (fig 2,3).

\subsection{Postoperative Follow Up}

Revision of the wound in the operating theatre was done on first postoperative day and revealed good tissue status. Patient admitted to the ICU and started on IV Meropenem $500 \mathrm{mg} \times 3$ and IV Clindamycin $600 \mathrm{mg}$ x3. Daily wound dressing was done in the ICU. Patient moved to the Urology ward after 3 weeks in a good status. After discussion with the patient and the family, decided to suture the wound without periniostomy and permanent Supra-pubic catheter.

\subsection{Three months follow up}

Follow up visit in the Urology clinic after 3 months confirmed a good wound status and well functioning suprapubic catheter.

\section{Discussion}

Fournier's gangrene is a disease caused by polymicrobial necrotizing fasciitis of the urogenital and perineal areas. Early intervention including administration of antibiotics and emergency operative management are essential. However, mortality still approach 67\% despite advancements in diagnostic modalities and intensive care management [7]. Early treatment aims to decompress the abscesses as soon as possible. Numerous studies confirmed that the cornerstone of treatment for patients with FG is the 


\section{International Journal of Science and Research (IJSR) \\ ISSN (Online): 2319-7064}

Index Copernicus Value (2013): 6.14 | Impact Factor (2014): 5.611

early and radical surgical removal of the necrotic tissue $[2,6,8]$. Furthermore, a conservative treatment based on the use of strong wide spread antibiotics associated to Hyperbaric oxygen (HBO) therapy can eliminate the need for repeated surgical debridement [9]. There is no consensus on which different clinical variables determine the poor outcome in patients with FG [8]. Many studies suggested higher mortality rate for patients who had more frequent operations when a greater extent of the disease exist [6]. Palmer et al. showed that repeated debridements, even if performed within the first $24 \mathrm{~h}$ of presentation, had no effect on the outcome [10].

\section{Conclusion}

In conclusion, Fournier's Gangrene is a rapidly progressive, life threatining infection. With aggressive treatment modalities, including early surgical intervention, haemodynamic support, intensive care monitoring and broad-spectrum antibiotic coverage, the disease has a greatly reduced mortality rate.

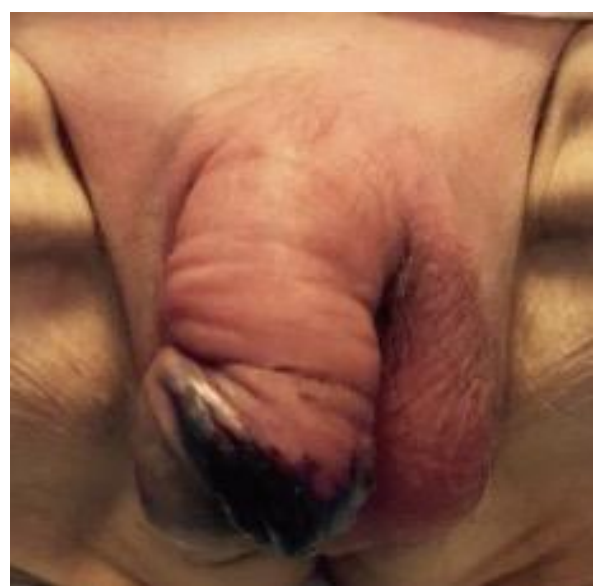

Figure 1: Image demonstrating swelling and gangrene in the penis.

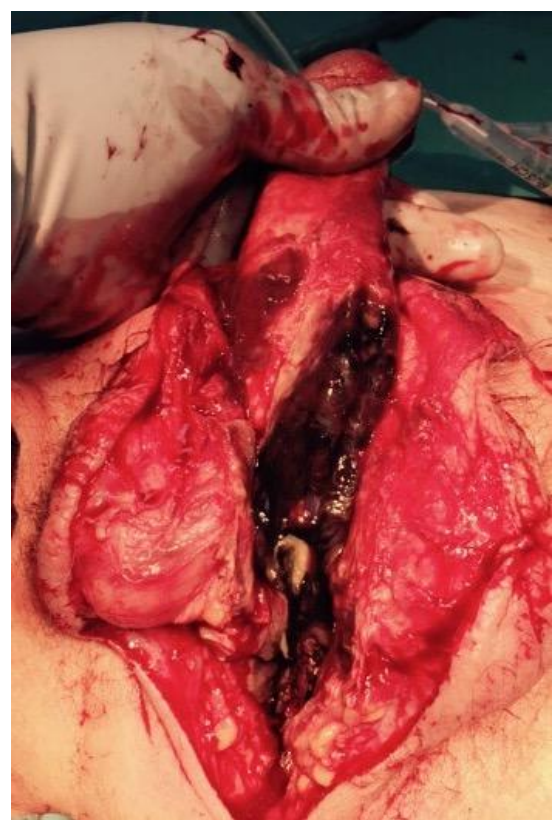

Figure 2: Intraoperative image demonstrating gangrene in the penis and the urethra

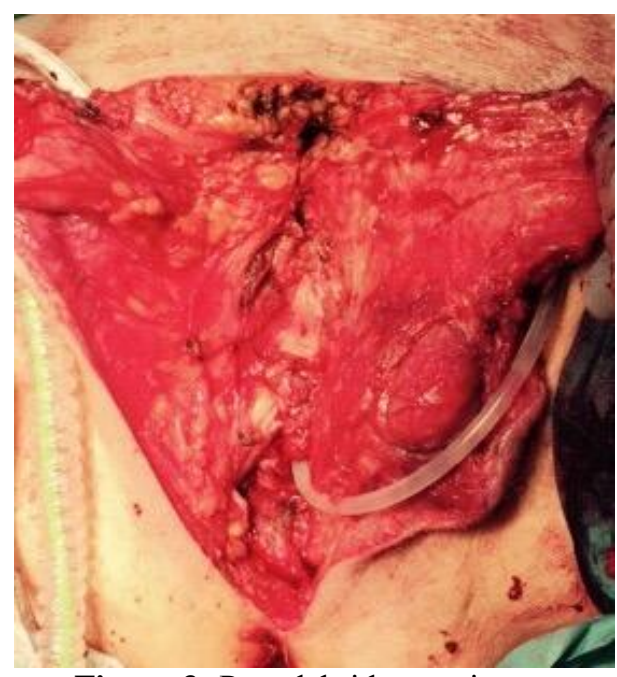

Figure 3: Post debridement image

\section{References}

[1] Luján Marco S, Budía A, Di Capua C, Broseta E, Cruz FJ. Evaluation of a severity score to predict the prognosis of Fournier's gangrene. BJU international. 2010;106(3):373-6.

[2] Eke N. Fournier's gangrene: a review of 1726 cases. British Journal of Surgery. 2000;87(6):718-28.

[3] Jeong HJ, Park SC, Seo IY, Rim JS. Prognostic factors in Fournier gangrene. International journal of urology. 2005;12(12):1041-4.

[4] Ersay A, Yilmaz G, Akgun Y, Celik Y. Factors affecting mortality of Fournier's gangrene: review of 70 patients. ANZ journal of surgery. 2007;77(1-2):43-8.

[5] Yeniyol CO, Suelozgen T, Arslan M, Ayder AR. Fournier's gangrene: experience with 25 patients and use of Fournier's gangrene severity index score. Urology. 2004;64(2):218-22.

[6] Tuncel A, Aydin O, Tekdogan U, Nalcacioglu V, Capar Y, Atan A. Fournier's gangrene: Three years of experience with 20 patients and validity of the Fournier's Gangrene Severity Index Score. European urology. 2006;50(4):838-43.

[7] Corman J, Moody J, Aronson W. Fournier's gangrene in a modern surgical setting: improved survival with aggressive management. BJU international. 1999;84:858 .

[8] Corcoran A, Smaldone M, Gibbons E, Walsh T, Davies B. Validation of the Fournier's gangrene severity index in a large contemporary series. The Journal of urology. 2008;180(3):944-8.

[9] Milanese G, Quaresima L, Dellabella M, Scalise A, Di Benedetto GM, Muzzonigro G, et al. A conservative approach to perineal Fournier's gangrene. Archivio Italiano di Urologia e Andrologia. 2015;87(1):28-32.

[10] Palmer L, Winter H, Tolia B, Reid R, Laor E. The limited impact of involved surface area and surgical debridement on survival in Fournier's gangrene. British journal of urology. 1995;76(2):208-12. 